\title{
USAGE OF METHYL ESTER PRODUCED FROM WASTE GRAPE AND MN ADDITIVE AS ALTERNATIVE DIESEL FUEL
}

\author{
Hanbey HAZAR ${ }^{1}$, Mahmut UYAR ${ }^{2}$,Huseyin AYDIN ${ }^{3}$, Emine SAP \\ ${ }^{1}$ Department of Automotive Engineering, Technology Faculty, Firat University, Elazig, Turkey \\ hanbeyhazar@hotmail.com \\ ${ }^{2}$ Surt Vocational School of Higher Education, Surt University, Surt, Turkey \\ 2mahmutyar2011@hotmail.com \\ ${ }^{3}$ Department of Mechanical Engineering, Engineering Faculty, Batman University, Batman Turkey \\ 3huseyyinaydin@gmail.com \\ ${ }^{4}$ Vocational School of Higher Education, Bingol University, Bingol, Turkey \\ 4esap@bingol.edu.tr
}

\begin{abstract}
In this study, methyl ester was produced from waste grape pulp sources. The produced methyl ester was mixed with diesel in different proportions, and was tested for engine performance and emission. It was found that with increasing biodiesel content, the specific fuel consumption and exhaust temperature have increased partially, while the CO, HC and smoke emissions decreased significantly. Additionally, in the scope of this study, dodecanol, propylene glycol and Mn based additives were added to fuel B50 to improve the emission and engine performance values. With the presence of additives, an increase in the exhaust temperature was observed, while a decrease in the specific fuel consumption, $\mathrm{CO}, \mathrm{HC}$, and smoke emissions were detected.
\end{abstract}

Keywords:diesel engine, biodiesel, grape seed oil, Mn additive, engine performance

\section{Introduction}

Oil based fuels are used in diesel engines which have a broad spectrum of application. In parallel to the increase in world population and technological developments, fields that obtain their energy requirements from diesel engines will be negatively affected in case oil fields are be able to meet the demand and the oil prices rise. In addition, exhaust fumes that are released as a result of combusting oil based fuel in diesel engines cause pollution that are bordering on the acceptable limits. For these reasons, it is necessary that the oil-based consumption is decreased, and in order to decrease the emissions from these engines, an alternative fuel is required.The fuel used in diesel engines should be economical, renewable, environmentally friendly, and have a quality that is easily obtained. In recent years, vegetable, animal and chemical oils with different properties have been produced for biodiesel. Biodiesel can be used in diesel engines with few or no modifications. Even though they give out better emissions compared to standard diesel fuel, some negative factors (higher viscosity, high freezing point, poor atomization and low thermal value) that affect the engine performance were observed in the conducted studies when biodiesel mixtures are used directly in the diesel engine [1].

Biodiesel can be mixed into the diesel fuel in different ratios.With these studies, the aforementioned problems were solved, but it was stressed that as the combustion yield was low, fuel consumption and exhaust emission values should be improved [2]. It was also seen that depending on the amount of biodiesel added to the standard diesel fuel the freezing point increases. This is related to the performance decrease of engines that use biodiesel; in fact, it may also cause the engine to stop working. Under these circumstances, using an additive in engines that use biodiesel is inevitable. A number of studies were conducted to find solutions to the problem mentioned above. In the conducted studies, additives such as cerium (Ce), cerium-iron (Ce-Fe), platinum (Pt), platinum-cerium (Pt-Ce), iron (Fe), molybdenum (Mo), manganese (Mn), nickel (Ni) and magnesium (Mg) were added to the biodiesel containing fuel [3-5] In the work, we intend to produce methyl ester from the waste grape seed oil at optimized conditions and improve the fuel's properties with manganese additive, as a novel process. Diesel fuel and blend of waste grape seed methyl ester doped magnesium 
additive with diesel fuel (50\%) were tested in a direct injection diesel engine at different load conditions. Additionally, in the scope of this study, dodecanol, propylene glycol additives were added to fuel B50 to improve the emission and engine performance values.

\section{Materials and Methods}

\subsection{Test fuel}

Grape is the raw material for vinegar, wine and fruit juice. In these fields, after the grape juice is obtained, the seed and pulp is considered to be waste. The seed, which is now idle, can be processed in a screw press to separate the oil and the pulp. Recently, the grape pulp oil that is obtained as a result of this process has found use in the pharmaceutical field, but when the total reserve is considered, it has sufficient capacity to be considered as an alternative in biodiesel.Although biodiesel can be produced by every oil type that is used in households, obtaining the required quality and yield is related to the property of the oil. In order to obtain high quality biodiesel production, the reaction type that is to be carried out must be determined first. It is based on significantly the free fatty acid ratio of the oil that is to be used. Before the biodiesel production process was designed, the free fatty acid ratio was obtained in this study. The results of the chemical analysis in terms of stearic and oleic acid are given in Table 1 . Based on the analysis results, the most appropriate method is determined as base catalyzed transesterification.

Table 1 . Free fatty acid rates in terms of stearic and oleic acid.

\begin{tabular}{lcc}
\hline Oil type & Stearic acid (\%) & Oleic acid (\%) \\
$\begin{array}{l}\text { Waste grape } \\
\text { seed oil }\end{array}$ & 2.51 & 2.50 \\
\hline
\end{tabular}

$1000 \mathrm{ml}$ waste grape seed oil was mixed in a three dimensional flask, using a magnetic stirrer at $500 \mathrm{rpm}$ and $60^{\circ} \mathrm{C}$. Methanol was added to another magnetic stirrer such that it was $20 \%$ of the oil used $(200 \mathrm{ml})$ and sodium hydroxide salt $(\mathrm{NaOH})$ was also added in an amount that is $0.4 \%$ of the oil used. The mixture was mixed until the $\mathrm{NaOH}$ salts were dissolved completely. After $\mathrm{NaOH}$ was dissolved completely in methanol, the solution was gradually added to the grape seed oil that is being stirred at $60{ }^{\circ} \mathrm{C}$. The transesterification reaction was carried out in a condenser system for 2 hours. After the product taken its final form, it was filtered and stored. The physical and chemical properties of the obtained biodiesel are given in Table 2.
Table 2. Physical and chemical properties of the test fuels.

\begin{tabular}{lcc}
\hline Property & Diesel Fuel & GSOME \\
Viscosity (Mpa.s) & 4.24 & 4.656 \\
Density $\left(\mathrm{Kg} / \mathrm{m}^{3}\right)$ & 831.96 & 879.1 \\
Flash Point $\left({ }^{\circ} \mathrm{C}\right)$ & 65.5 & 143.7 \\
Cetane Index & 53.1 & 58.7 \\
Pour Point $\left({ }^{\circ} \mathrm{C}\right)$ & -14 & -5 \\
Clorific Value (Cal/gr) & 9302 & 9030 \\
\hline
\end{tabular}

The biodiesel that has been obtained as a result of chemical processes is mixed with SHELL brand biodiesel in 20\%, 35\%, 50\%, 75\%, and $100 \%$ in volume to prepare the samples. Whereas for the samples that contain additives, 1 lt (50\%) diesel fuel was mixed with 1 lt (50\%) biodiesel, and $20 \mathrm{ml}$ (1\%) dodecanol, $100 \mathrm{ml}$ (5\%) propylene glycol and different dosages of $\mathrm{Mn}(20-40-60 \mu \mathrm{mol} / \mathrm{lt})$ were added. The goal to add additives to fuel samples is to obtain the optimal physical and chemical properties. Since there was no metal-based study with the produced waste grape oil methyl ester, the study was carried out in a wide range.

\subsection{Engine test apparatus and method}

The experimental study was realized in a Genpower brand diesel generator. During the study, no modifications were done on the engine, generator or on any other component. The fuel samples were tested under the same conditions. The technical properties of the diesel engine are given in Table 3 . The engine test setup is shown in Figure 1.

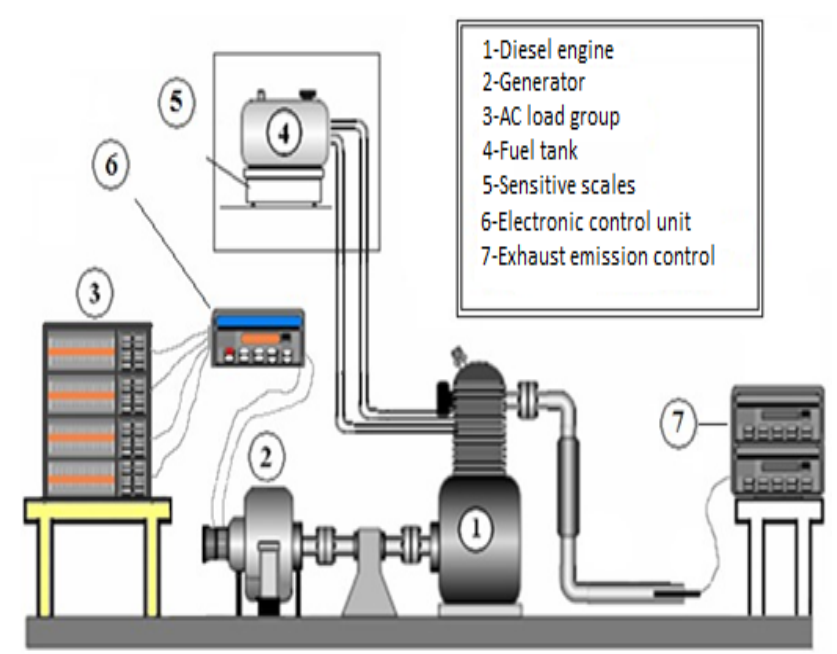

Fig. 1. Schematic diagram of the engine test bed. 
Table 3. Test engine specifications.

\begin{tabular}{ll}
\hline Item & INTER-IDE314NG \\
$\begin{array}{l}\text { Spray system } \\
\text { Cooling system }\end{array}$ & $\begin{array}{l}\text { Direct injection } \\
\text { Water-cooled }\end{array}$ \\
Number of cylinders & 3 \\
Bore x Stroke & $80 \times 90$ \\
Stroke volume (lt) & 1.4 \\
Compression ratio & $18 / 1$ \\
Maximum power $\quad(\mathrm{kW} / \mathrm{HP})$ & $13.5 / 18$ \\
\hline
\end{tabular}

In the experiments, a synchronous generator with the maximum active power of $12.5 \mathrm{~kW}$ was used to start the engine. The engine worked with standard fuel without load for period of time, and when the engine reached the optimal temperature, 4 different load levels of $2.5 \mathrm{~kW}(20 \%)-5 \mathrm{~kW}(40 \%)-7.5 \mathrm{~kW}$ $(60 \%)-10 \mathrm{~kW}(80 \%)$ were applied on the engine. This procedure was repeated twice and the averages of the values were calculated. In the different loads, the specific fuel consumption (gr/kWh), HC (ppm), CO (\%), exhaust temperature $\left({ }^{\circ} \mathrm{C}\right)$ and smoke values were measured.

2.3. The evaluation of performance, combustion characteristics and exhaust emissions

The SFC value of biodiesel was compared with that of diesel. When biodiesel was compared with diesel, it was seen that there was an increase of $5 \%$ with B20 fuel, 9.1\% with B35, 13.3\% with B50, 17.7\% for B75, and $20.4 \%$ with B100.The SFC values are shown in

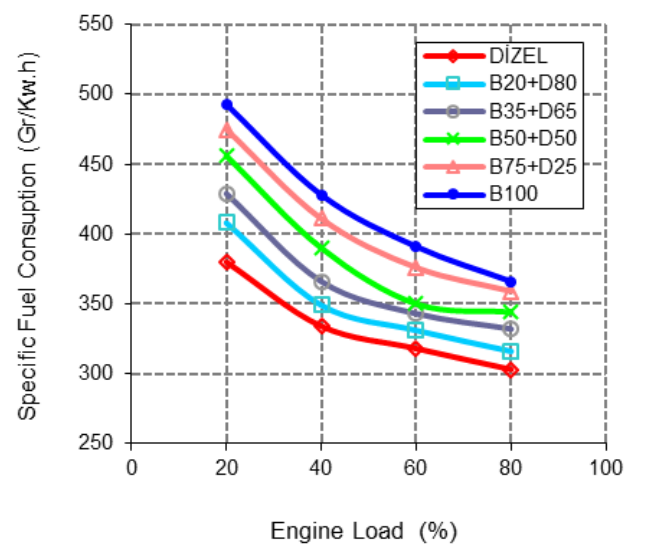

(a)

Fig. 2 (a).

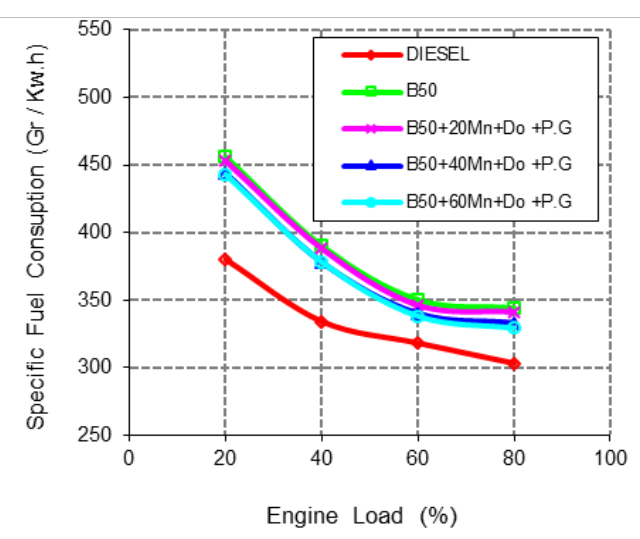

(b)

Fig.2. Variation of SFC at different engine loads for various fuels. (a) Biodiesel, (b) B50 with additives

As seen in Figure 2(a), the lowest specific consumption was obtained when the diesel with the lowest value was used, and the highest specific consumption was obtained with B100. The SFC values of the fuels increase proportionally with increasing biodiesel amount in mixtures. This increase is thought to be related to the low thermal vale and the high viscosity and density of biodiesel. As seen on Figure 2(a), even though the biodiesel and diesel were tested under the same load, and produced the same power, the SFC of biodiesel as higher than that of diesel. This was thought to be due to three reasons. First, the amount of biodiesel sent off the injection pump increases due to higher density. In other words, it is inevitable to come up with a high SFC value for high density fuels. The second reason is the viscosity difference between the fuels. When high viscosity fuels are sent to the combustion chamber from the same injection nozzle, they end up having bigger particles. Another factor that affects the SFC is the thermal value of the fuel. As every sample was tested under the same loading conditions, the same energy is expected to be obtained at the end of combustion. In order to obtain the same amount of thermal energy, a larger amount of biodiesel needs to be sent to the combustion chamber. As a result, the density, viscosity and thermal values of the injected fuel affects the SFC [6]. The SFC of B50 was compared to the SFC values of fuels with additives. When the SFC values of the fuels with additives were compared with B50 fuel, a decrease of $1 \%$ was observed in $\mathrm{B} 50+20 \mathrm{Mn} \mu \mathrm{mol} / \mathrm{lt}+\mathrm{PG}$ fuel, $3 \%$ decrease was seen in $\mathrm{B} 50+40 \mathrm{Mn} \mu \mathrm{mol} / \mathrm{lt}+\mathrm{PG}$, and $3.05 \%$ decrease in $\mathrm{B} 50+60 \mathrm{Mn} \mu \mathrm{mol} / \mathrm{lt}+\mathrm{PG}$ was observed. The SFC values are shown in Figure 2 (b). The effect of the additives on the declining SFC can be seen on Figure 2(b). It is thought that the additives improve the cetane number, viscosity, density and the flash point, and they also have a catalyzing role in combustion, which is thought to decrease the SFC value. In addition, when the $\mathrm{Mn}$ additive amount increased in B50, a further decline in SFC was observed, whichcan be seen in Figure 2(b). It was pointed out that adding 
metal based additives to fuel improves the cetane number, viscosity and flash point. However, it was also pointed out that there was an optimal amount of additives, and when this amount was exceeded, the cetane number, density, viscosity and flash point was negatively affected [7]. 20, 40, $60 \mu \mathrm{mol} / \mathrm{lt}$ of Mn was added to the B50 fuel, which was produced in Grape Seed Oil Methyl Ester (GSOME). Figure 2(b) shows that the best performance was given in the 40 $\mu \mathrm{mol} / \mathrm{ltMn}$ that was added.Thermal efficiency is calculated via the following formula using the specific fuel consumption and lower heating value.

$\eta=\frac{36}{b_{e} H_{u}} \times$

Where $\eta$ isthermal efficiency (\%), $b_{e}$ is specific fuel consumption $(\mathrm{kg} / \mathrm{kWh})$ and $\mathrm{Hu}$ islower heating value $(\mathrm{kj} / \mathrm{kg})$.In internally combustible engines, the heat energy produced as a result of the burning of fuel inside the burning chamber is transformed into mechanical energy. Effective efficiency gives information as to what portion of the heat energy was transformed into useful work. The effective efficiency values for all fuels under all load conditions were calculated and given in Figure 3(a).

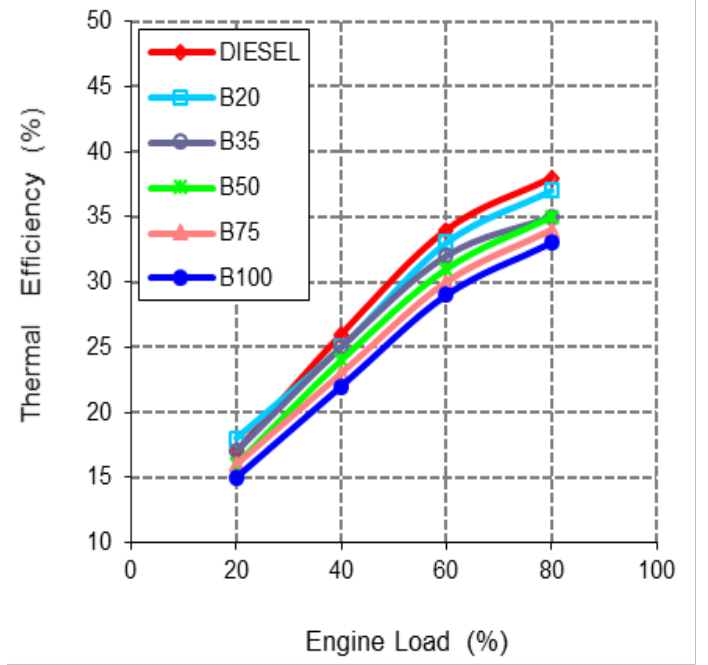

(a)

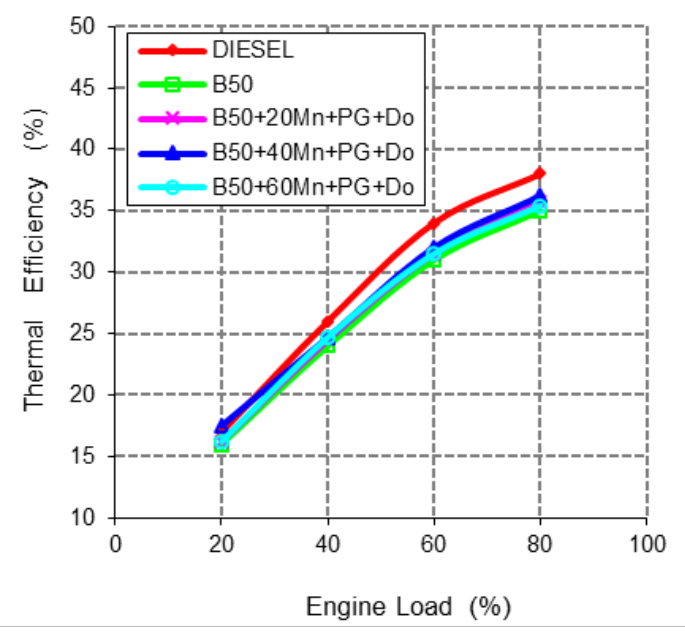

(b)

Fig. 3. Variation of thermal efficiency at different loads for various fuels. (a) Biodiesel, (b) B50 with additives.
The thermal efficiency value of biodiesel was compared with that of diesel. When biodiesel was compared with diesel, it was seen that there was a decrease of $0.4 \%$ with B20 fuel, $3.7 \%$ with B35, $6.6 \%$ with $\mathrm{B} 50,9.8 \%$ for $\mathrm{B} 75$, and $12.4 \%$ with $\mathrm{B} 100$. It is observed in Figure 3(a) that the effective efficiency in biodiesel usage is lower in comparison with the ratio in diesel fuel usage. The highest efficiency was obtained with diesel fuel whereas the lowest efficiency was determined with B100 fuel. The low value of effective efficiency in the motor during biodiesel usage leads us to think that this is due to the high viscosity value of biodiesel fuel and its low heating value. Bad atomization and low heating value in biodiesel usage due to high viscosity resulted in a low brake effective efficiency in comparison with that of diesel fuel [8]. The thermal efficiency of B50 was compared to the thermal efficiency values of fuels with additives. When the thermal efficiency values of the fuels with additives were compared with B50 fuel, an increase of $2.1 \%$ was observed in $\mathrm{B} 50+20 \mathrm{Mn} \mu \mathrm{mol} / \mathrm{lt}+\mathrm{PG}$ fuel, $3.05 \%$ increase was seen in $\mathrm{B} 50+40 \mathrm{Mn} \mu \mathrm{mol} / \mathrm{lt}+\mathrm{PG}$, and $2.05 \%$ increase in B50+60Mn $\mu \mathrm{mol} / \mathrm{lt}+\mathrm{PG}$ was observed. The effective efficiency values for all fuels under all load conditions were calculated and given in Figure 3(b).It is seen in Figure 3(b) that the addition of additives to B50 fuel has increased effective efficiency. It is thought that the addition of additives to the fuel have positive contributions to properties such as cetane number, viscosity and flash point [9]. However, it has also been stated that there is an optimum value for the addition of metal based additives to the fuel and that the properties such as cetane number, density, viscosity and flash point will be affected negatively when this value is exceeded [9].Mndosings of 20, 40 and $60 \mu \mathrm{mol} / \mathrm{lt}$ have been made to B50 fuel prepared from GSOME. It is observed from Figure 3(b) that the best effective efficiency increase among the aforementioned scales is for Mn usage at $40 \mu \mathrm{mol} / \mathrm{lt}$ scale. It is thought that heating value and viscosity problems in biodiesel fuels may increase friction losses in the motor and also increase the effective efficiency in biodiesels due to the solution of heat transfer losses [4].

The CO emissions of biodiesels were compared with diesel. When biodiesel was compared to diesel in terms of $\mathrm{CO}$, a decrease of $33.1 \%$ was observed in B20, 34\% decrease was observed in B35, 35\% decrease was observed in B50, 45\% decrease was observed in B75 and 51.1\% decrease was observed in B100.The CO emissions for all fuels under all load conditions were calculated and given in Figure 4(a). 


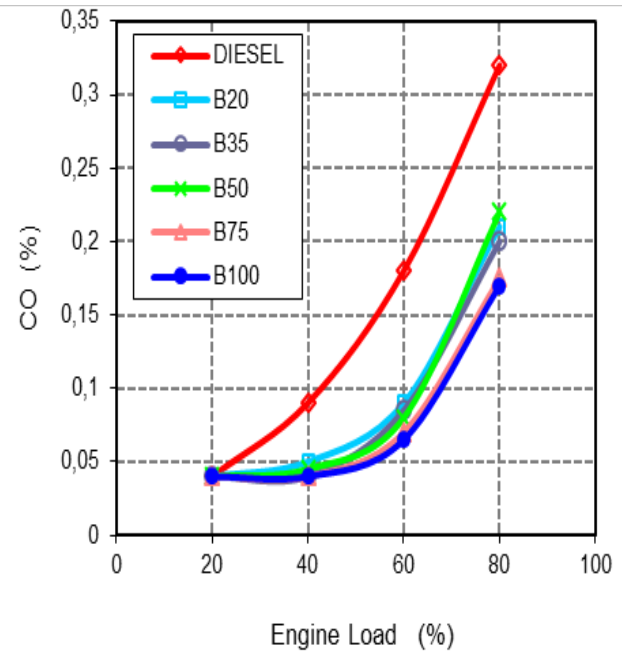

(a)

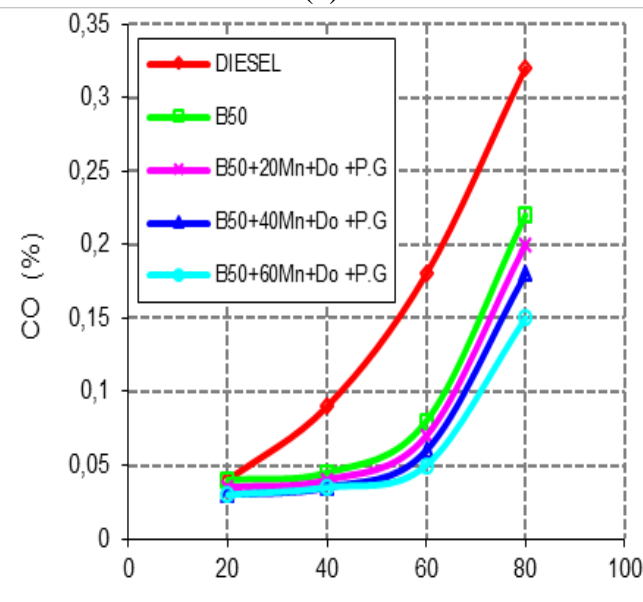

Engine Load (\%)

(b)

Fig. 4. Variation of $\mathrm{CO}$ at different engine loads for various fuels.

(a) Biodiesel, (b) B50 with additives.

Figure 4(a) shows that the $\mathrm{CO}$ emission increases in parallel to increasing load. The increase in CO emission with increase in load was related to the increase in fuel consumption. Figure 4(a) also shows that the $\mathrm{CO}$ emissions of biodiesel are less than that of diesel fuel. The cetane count of biodiesel is high, and the chemical structure contains oxygen; these factors are thought to affect the decrease in $\mathrm{CO}$ emissions. Oxygen content in biodiesel contributes to better oxidation processes within the combustion chamber. This reduces $\mathrm{CO}$ emission and promotes higher $\mathrm{NO}_{\mathrm{x}}$ emission. The advanced start of injection, caused by biodiesel usage, also contributes to a higher production of $\mathrm{NO}_{\mathrm{x}}$ emissions [4]. At 20\% load, the $\mathrm{CO}$ emissions of the test fuels were similar values, but when the load went up to $40 \%, 60 \%$ and $80 \%$, significant differences in CO emissions could be observed, as seen in Figure 4(a). With the increase in biodiesel amount in diesel fuel, the cetane count and oxygen content increases, and this causes different amounts of $\mathrm{CO}$ emission. It is thought that with better properties for combustion performance will decrease
$\mathrm{CO}$ emissions. The $\mathrm{CO}$ emissions of $\mathrm{B} 50$ fuel were compared to that of $\mathrm{B} 50+20 \mathrm{Mn}+\mathrm{PG}, \mathrm{B} 50+40 \mathrm{Mn}+\mathrm{PG}$ and $\mathrm{B} 50+60 \mathrm{Mn}+\mathrm{PG}$ fuel. When the fuels are compared to the CO emission of B50,9.9\% decrease in B50+20Mn+PG fuel, 20.1\% decrease was observed in $\mathrm{B} 50+40 \mathrm{Mn}+\mathrm{PG}$, and a $30.4 \%$ decrease was observed in B50+60Mn+PG. The CO emissions for all fuels under all load conditions were calculated and given in Figure 4(b). The emission values of fuels with additives have lower $\mathrm{CO}$ emission than $\mathrm{B} 50$, as seen on Figure 4(b). The additives improve the cetane count, the flash point, viscosity and density, which improves the combustion yielding better results in comparison with those of B50 [9]. As seen in Figure 4(b), with increasing $\mathrm{Mn}$ content, the o emissions have decreased. Mn based additives improve the properties that affect combustion performance [4]. It is thought that improved combustion performance gives time for $\mathrm{CO}$ to convert to $\mathrm{CO}_{2}$. The most important factor in the production of $\mathrm{HC}$ emissions is the gases that remain from the previous cycle. The remaining gases in the combustion chamber are mixed with compressed air. This decreases the oxygen content of the new air-fuel mixture, which causes the HC emissions[9]. The HC emissions of biodiesels were compared with diesel. When biodiesel was compared to diesel in terms of $\mathrm{HC}$, a decrease of $40.5 \%$ was observed in B20, 50.6\% decrease was observed in B35, 55.3\% decrease was observed in B50, 60.5\% decrease was observed in B75 and 74.9\% decrease was observed in B100.The HC emissions for all fuels under all load conditions were calculated and given in Figure 5(a).

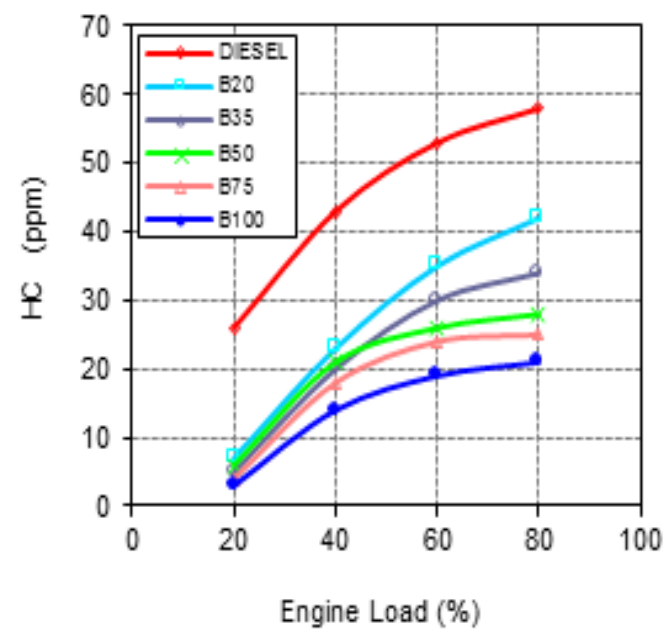

(a) 


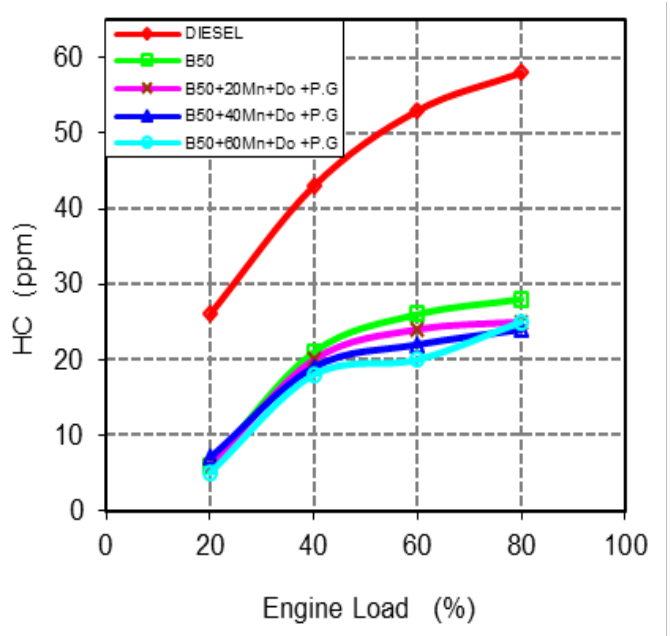

(b)

Fig. 5. Variation of HC at different engine loads for various fuels.

(a) Biodiesel, (b) B50 with additives.

The decrease in HC emissions with the use of biodiesel is shown in Figure 5(a). This decrease is thought to be related to the oxygen content in biodiesel. The oxygen content in biodiesel is thought to support the combustion reaction, thus decreasing the HC emissions. The fact that every sample has varying amount of oxygen and the increase in cetane count in correspondence to the increasing biodiesel amount can be shown as the reason for this difference. With the increase in load, all of the fuels showed an increase in $\mathrm{CO}$ emission. This could be explained with the increase of the load causing a parallel increase in the fuel consumption. The oxygen content in biodiesel decreases the $\mathrm{CO}, \mathrm{HC}$ and smoke emissions, because with the oxygen content, complete combustion takes place, and this contributes to decreasing HC emissions. In addition, the cetane count, boiling point, sulfur anaromatic content also have an effect in the $\mathrm{HC}, \mathrm{CO}$ and smoke emissions. The HC emissions of B50 fuel were compared to that of B50+20Mn+PG, $\mathrm{B} 50+40 \mathrm{Mn}+\mathrm{PG}$ and $\mathrm{B} 50+60 \mathrm{Mn}+\mathrm{PG}$ fuel. When the fuels are compared to the HC emission of B50, $6.25 \%$ decrease in $\mathrm{B} 50+20 \mathrm{Mn}+\mathrm{PG}$ fuel, $10 \%$ decrease was observed in B50+40Mn+PG, and a 15\% decrease was observed in B50+60Mn+PG.The HC emissions for all fuels under all load conditions were calculated and given in Figure 5(b). When additives are present in the fuel, the $\mathrm{HC}$ emissions decrease in comparison with B50, as seen in Figure 5(b). It is considered that the additives increase the cetane count and oxygen content, and contributes to improving combustion performance. The high oxygen content of propylene glycol and dodecanol's oxygen content and the effect of $\mathrm{Mn}$ on cetane count is considered to be the contributors. If the cylinder is working with a slow cycle, the combustion performance will be low, because the temperature in slower cycles is not optimal which causes a poor combustion reaction [9]. The smoke emissions of biodiesels were compared with diesel. When biodiesel was compared to diesel in terms of smoke emissions, a decrease of $25 \%$ was observed in B20, 29\% decrease was observed in B35, $35.2 \%$ decrease was observed in B50, 49\% decrease was observed in B75 and 61\% decrease was observed in B100. The smoke emissions for all fuels under all load conditions were calculated and given in Fig. 6(a).

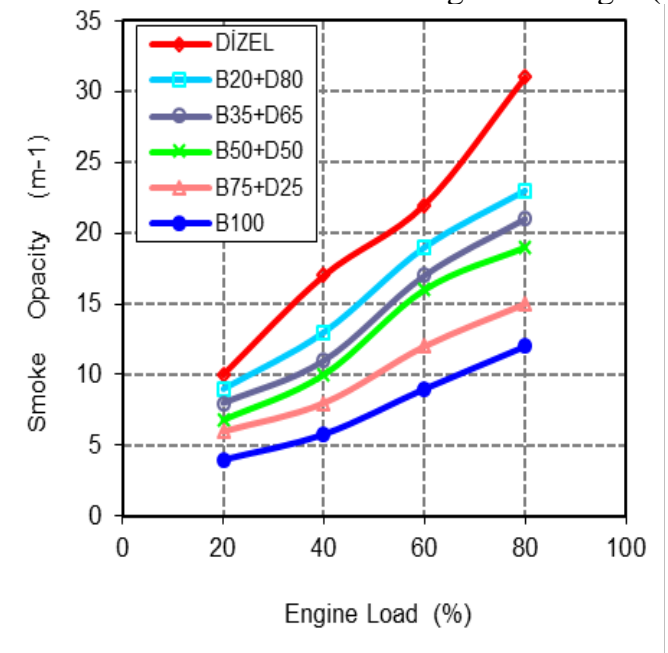

(a)

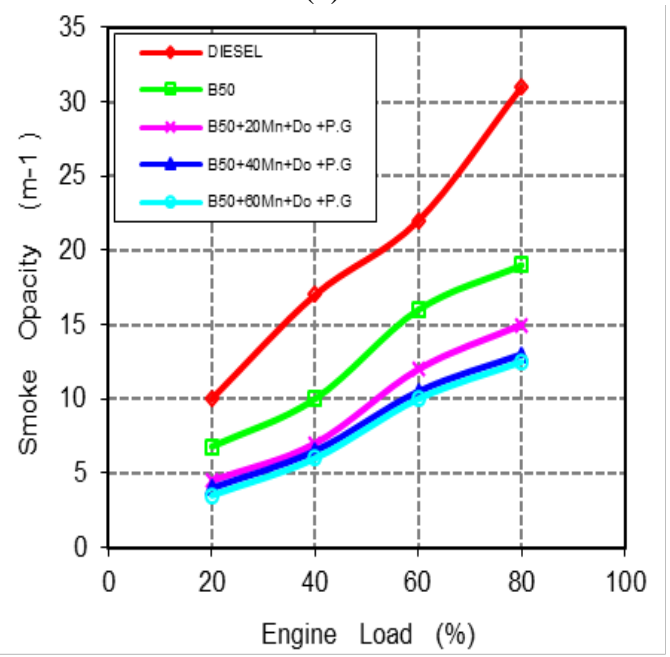

(b)

Fig. 6. Variation of smoke opacity at different engine loads for various fuels.

(a) Biodiesel, (b) B50 with additives

The reason that smoke emissions are lower when biodiesel is used could be explained by the oxygen content. Also, biodiesel has lower carbon count compared to diesel, which increases oxidation during combustion, that decreases smoke emission as a result. The decrease in smoke emissions with increasing biodiesel amount can be seen in Figure 6(a).It is stated that the oxygen content of biodiesel causes a significant decrease in smoke emissions [4]. It is also stated that the lowered carbon content affects this situation. Oxygen containing fuels increase the temperature of the cylinder. This increase affects the combustion yield positively by preventing regional temperature difference. Changes in regional temperature and oxygen concentration distribution are 
considered to be the main reasons in soot formation [4]. The smoke emissions of B50 fuel were compared to those of $\mathrm{B} 50+20 \mathrm{Mn}+\mathrm{PG}, \mathrm{B} 50+40 \mathrm{Mn}+\mathrm{PG}$ and $\mathrm{B} 50+60 \mathrm{Mn}+\mathrm{PG}$ fuel. When fuels are compared to the smoke emission of B50, 25.8\% decrease in B50+20Mn+PG fuel, 33.7\% decrease was observed in $\mathrm{B} 50+40 \mathrm{Mn}+\mathrm{PG}$, and a $38.1 \%$ decrease was observed in B50+60Mn+PG. The smoke emissions for all fuels under all load conditions were calculated and given in Fig.6(b).As seen in Figure 6(b), with the addition of additives, the smoke emissions decrease. The oxygen content of the additives is more than that of biodiesel. Supporting B50 with $\mathrm{Mn}$, propylene glycol, and dodecanol decreases the carbon content and increases the oxygen content. It is considered that the increasing oxygen content speeds up the oxidation reaction and decreases smoke emissions [10]. Also, the additives give stability to the combustion reaction, which prevents turbulent mixing zones in the flame and smoke emissions.Some of the heat energy gained by the combustion of fuel in the cylinder is lost to cooling, exhaust and friction. The remaining heat energy is converted to mechanical energy to provide power to the engine.

\section{Conclusions}

In this study, methyl ester was produced from waste grape pulp sources. The produced methyl ester was mixed with diesel in B20, B35, B50, B75 and B100 proportions, and was tested for engine performance and emission.Based on the obtained results, the following conclusions can be drawn:

$>\quad$ The engine performance run by grape seed methyl ester and its blends are comparable with the performance run by pure diesel fuel.

$>$ When the aforementioned fuel samples were compared to diesel fuel, it was found that with increasing biodiesel content, the specific fuel consumption and exhaust temperature have increased partially, while the $\mathrm{CO}, \mathrm{HC}$ and smoke emissions decreased significantly.

$>$ Additionally, in the scope of this study, dodecanol, propylene glycol and $\mathrm{Mn}$ based additives were added to fuel B50 to improve the emission and engine performance values. With the presence of additives, an increase in the exhaust temperature was observed, while a decrease in the specific fuel consumption, CO, $\mathrm{HC}$, and smoke emissions were detected.

\section{Acknowledgements}

The authors would like to thank Firat University (FUBAP -Project No:TEF.11.10) for his support.

\section{References}

[1] Hazar, H., and Aydın, H. (2010),Performance and emission evaluation of a CI engine fueled with preheated raw rapeseed oil (RRO) diesel blends,Applied Energy,87, 786-790.

[2] Keskin, A., Gürü, M., and Altıparmak, D. (2010). The investigation of performance and emissions characteristics of Tall Oil biodiesel with a Co-based additive. Energy Sources Part A, 32, 1899-1907.

[3] Gürü, M., Karakaya, U., Altıparmak, D., Alıcılar, A. 82002). Improvment of diesel fuel properties by using additives. Energy Conversion \& Management, 43, 1021-1025.

[4] Kanan, G.R., Karvembu, R, and Anand, R. (2011).Effect of metal based additive on performance emission and combustion characteristics of diesel engine fuelled with biodiesel. Applied Energy, 88, 3694-3703.

[5] Okuda, T., Schauer, J.J., Olson, M.R., Shafer, M.M., Rutter, A.P., Walz, K.A., and Morschauser, P.A. (2009). Effects of a platinumcerium bimetallic fuel additive on the chemical composition of diesel engine exhaust particles. Energy Fuels, 23, 4974-4980.

[6] Hazar, H. (2010). Cotton methyl ester usage in a diesel engine equipped with insulated combustion chamber. Applied Energy, 87, 134-140.

[7] Keskin, A., Gürü, M., and Altıparmak, D. (2007). Biodiesel production from tall oil synthesized $M n$ and Ni based additives: effects of the additives on fuel consumption and emissions. Fuel, 86, 11391143.

[8] Lapuerta, M., Armas, O., and RodriguezFernandez, J. (2008). Effect of biodiesel fuels on engine emissions. Progress in Energy and Combustion Science, 34, 198-223.

[9] Puhana, S., Vedaramana, N., Rama, B.V.B., Sankarnarayananb, G., and Jeychandran, K. (2005). Mahua oil (madhucaindica seed oil) methyl ester as biodiesel-preparation and emission characteristics.Biomass and Bioenergy, 28, 87-93.

[10] Hazar, H., and Uyar, M. (2013). Investigation on the emission of grape seed methyl ester in a diesel engine, 6th international conference on sustainable energy and environmental protection, 20- 23 August, Maribor, Slovenia. 